\title{
Nicoya earthquake rupture anticipated by geodetic measurement of the locked plate interface
}

\author{
Marino Protti ${ }^{1}$, Victor González ${ }^{1}$, Andrew V. Newman ${ }^{2 \star}$, Timothy H. Dixon ${ }^{3}$, Susan Y. Schwartz ${ }^{4}$, \\ Jeffrey S. Marshall ${ }^{5}$, Lujia Feng ${ }^{6}$, Jacob I. Walter ${ }^{2}$, Rocco Malservisi ${ }^{3}$ and Susan E. Owen ${ }^{7}$
}

The Nicoya Peninsula in Costa Rica is one of the few places on Earth where the seismically active plate interface of a subduction zone is directly overlaid by land rather than ocean. At this plate interface, large megathrust earthquakes with magnitudes greater than 7 occur approximately every 50 years. Such quakes occurred in 1853, 1900 and 1950, so another large earthquake had been anticipated ${ }^{1,2}$. Land-based Global Positioning System ${ }^{3,4}$ (GPS) and seismic ${ }^{5-7}$ measurements revealed a region where the plate interface was locked and hence accumulated seismic strain that could be released in future earthquakes. On 5 September 2012, the longanticipated Nicoya earthquake occurred in the heart of the previously identified locked patch. Here we report observations of coseismic deformation from GPS and geomorphic data along the Nicoya Peninsula and show that the magnitude 7.6 Nicoya earthquake ruptured the lateral and down-dip extent of the previously locked region of the plate interface. We also identify a previously locked part of the plate interface, located immediately offshore, that may not have slipped during the 2012 earthquake, where monitoring should continue. By pairing observations of the spatial extent of interseismic locking and subsequent coseismic rupture, we demonstrate the use of detailed near-field geodetic investigations during the late interseismic period for identifying future earthquake potential.

The interface between convergent plates produces most of the world's largest earthquakes, threatening local inhabitants and global populations through destructive shaking and tsunami generation, as demonstrated by the recent $2011 M_{\mathrm{w}} 9.0$ TohokuOki and $2004 M_{\mathrm{w}} 9.15$ Sumatra-Andaman earthquakes and tsunami. Owing to the significant societal impacts, geoscientists endeavour to understand the driving and locking mechanisms controlling subduction zone seismicity. The shallow earthquakegenerating portion of the subduction interface, hereafter referred to as the megathrust, is difficult to characterize because it is relatively inaccessible, spans great lengths of continental margins and requires detailed near-field observations primarily in the marine environment.

In the late 1990s the Nicoya Peninsula of Costa Rica was recognized by the US National Science Foundation MARGINS programme as a focus area for seismogenic zone studies, in part because of the unique occurrence of land directly over the active subduction megathrust-normally, the megathrust seismogenic zone ends at or seaward of the coastline. The Cocos Plate subducts beneath the Caribbean Plate here at about $8.5 \mathrm{~cm} \mathrm{yr}^{-1}$ according to recent plate motion models ${ }^{8}$. Rapid plate convergence has generated magnitude 7+ earthquakes in 1853, 1900 and 1950 (Fig. 1). As a similar event was likely to occur, geophysical characterization of the state of the megathrust environment during what we'll refer to as the late interseismic was the focus of a number of studies aimed at evaluating the temporal and spatial variations in seismicity, the controls on asperities, energy partitioning during rupture and the nature of stress and strain through the seismic cycle.

Several recent studies developed detailed images of the geodetically locked interface both from global positioning system (GPS) data $^{3,4}$ and microseismicity ${ }^{5-7}$. These results, using independent but complementary data types, imaged a large, locked patch near the coastline of central Nicoya, roughly $60 \mathrm{~km}$ in length along-strike. At the periphery of this patch, studies identified a number of slow-slip events both down- and updip of the locked patch ${ }^{9,10}$ and associated low- to very-low-frequency earthquakes ${ }^{11-13}$. A well-developed seismic lineation was originally thought to be the seismogenic updip limit ${ }^{5}$, however geodetic locking was subsequently observed to exist both above and below this region ${ }^{3,4}$, suggesting that the location of microseismicity alone cannot identify the shallow extent of significant locking. The most recent projects established the dense network of broadband seismic and continuous GPS stations over the Nicoya Peninsula that recorded the 2012 earthquake in unprecedented detail.

The 2012 Nicoya earthquake occurred just after 08:42 am local time (14:42:05 coordinated universal time) on 5 September directly under the Nicoya Peninsula (Fig. 1). The event was expected, given recent studies that used geodetic and seismic means to illuminate plate coupling and buildup of elastic strain ${ }^{3,4,7,14,15}$. In part owing to recent efforts to raise awareness throughout the peninsula and develop and enforce building codes ${ }^{2}$ there were no confirmed human fatalities from this event even though local ground shaking was observed to be higher than $0.5 \mathrm{~g}$ on the peninsula, with a maximum value of almost $1.4 \mathrm{~g}$ near the epicentre ${ }^{16}$. No substantial tsunami was observed from this earthquake, consistent with expectations of previous studies ${ }^{17}$.

\footnotetext{
${ }^{1}$ Observatorio Vulcanológico y Sismológico de Costa Rica (OVSICORI), Universidad Nacional, Apartado 1718-3000, Heredia 3000, Costa Rica, ${ }^{2}$ School of Earth and Atmospheric Sciences, Georgia Institute of Technology, 311 Ferst Drive, Atlanta, Georgia 30332-0340, USA, ${ }^{3}$ Department of Geology, University of South Florida, 4202 E Fowler Ave, Tampa, Florida 33620, USA, ${ }^{4}$ Department of Earth and Planetary Sciences, University of California Santa Cruz, Santa Cruz, California 95064, USA, ${ }^{5}$ Geological Sciences Department, Cal Poly Pomona, 3801 West Temple Ave., Pomona, California 91768, USA, ${ }^{6}$ Earth Observatory of Singapore, Nanyang Technological University, 50 Nanyang Avenue, Block N2-1A-15, 639798, Singapore, ${ }^{7}$ Jet Propulsion Laboratory, MS 238-600, 4800 Oak Grove Drive, Pasadena, California 91109, USA. *e-mail: anewman@gatech.edu
} 

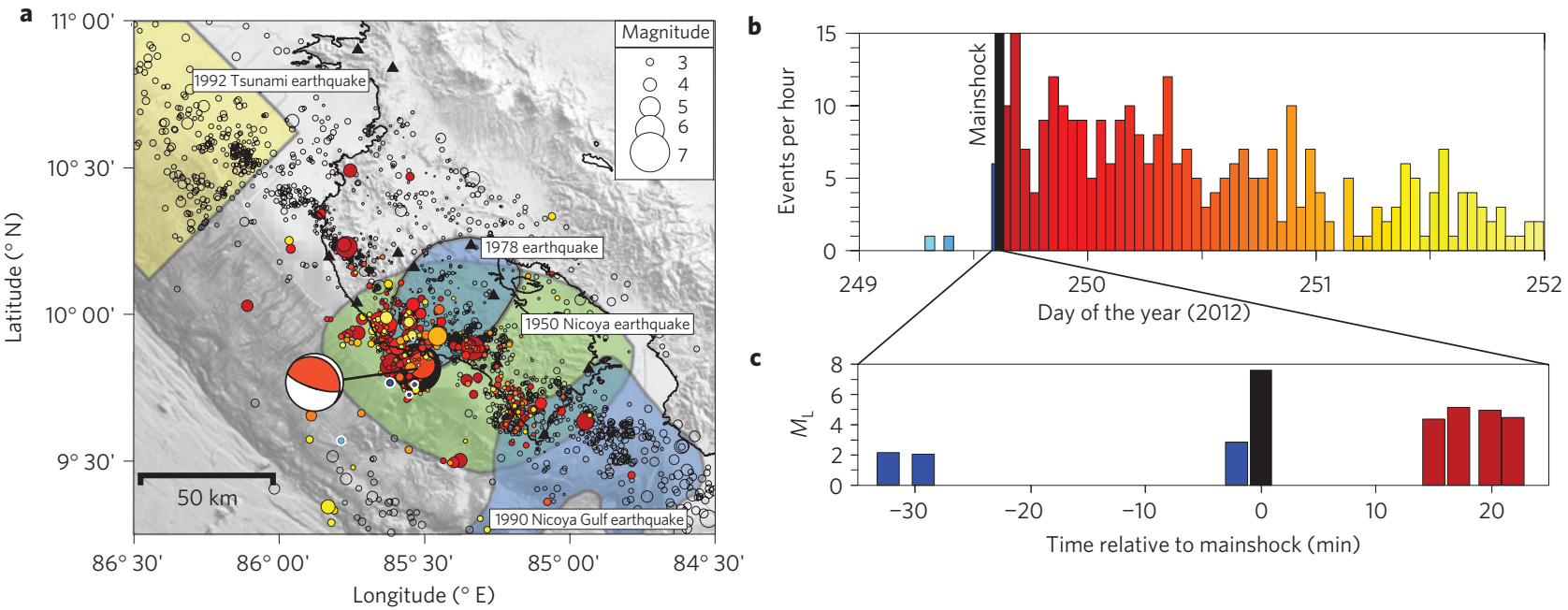

Figure 1 | Past large earthquakes, previous microseismicity and aftershocks. a, 5 September 2012 Nicoya earthquake, foreshocks (bordered in white) and early aftershocks (coloured by time of occurrence) are shown with past microseismicity ${ }^{7}$ (open circles) and large earthquakes (large coloured regions). The global Centroid Moment Tensor focal mechanism (beach ball) shows almost complete thrust. Large earthquakes occurred immediately to the southeast and northwest of Nicoya in 1990 and 1992. The Nicoya seismic network is shown (black triangles). b, Hourly binned histogram of seismicity shows the timing of early aftershocks (foreshocks shown in blue). c, Events in the one-hour bin during the mainshock include three foreshocks (blue).
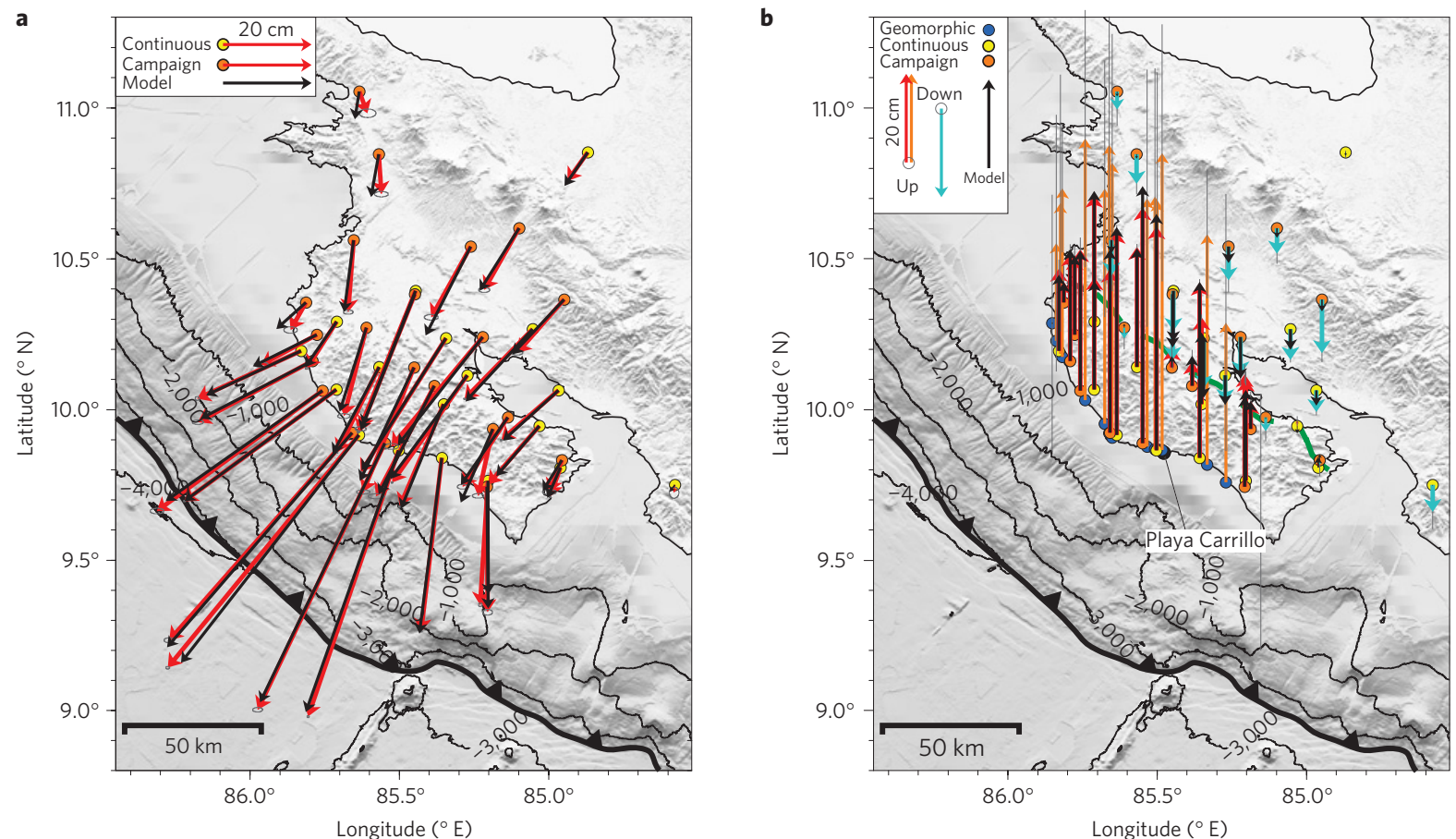

Figure 2 | Observed and modelled coseismic deformation of the 2012 Nicoya earthquake. $\mathbf{a}$, The horizontal and b, vertical coseismic displacements were observed by campaign and continuous GPS (red arrows from orange and yellow circles, respectively) and geomorphic observations (orange arrows from blue circles). The pivot line (green dashed line) marks the transition between uplift and subsidence. Errors are shown at 95 and $65 \%$ confidence for GPS and geomorphic data, respectively (solid grey ellipses and vertical bars). Playa Carrillo is the geomorphic change highlighted in Fig. 3. Also shown are the predicted (model) displacements from the preferred coseismic slip model shown in Fig. 4. GPS and geomorphic displacements are detailed in Supplementary Tables 1 and 2. Bathymetric contours in metres below sea level.

The earthquake initiated immediately seaward of the central portion of the peninsula and ruptured downdip with the most impulsive component occurring $3 \mathrm{~s}$ later ${ }^{18}$. Centroid moment tensor solutions roughly align with the axis of the trench and locate downdip of the initial hypocentre ${ }^{18,19}$ (Fig. 1). In the $32 \mathrm{~min}$ before the mainshock, three local magnitude $\left(M_{\mathrm{L}}\right) 2+$ foreshocks occurred within $25 \mathrm{~km}$ of the Nicoya earthquake epicentre (Fig. 1c). The largest and last foreshock $\left(M_{\mathrm{L}} 2.9\right)$ occurred just 2 min before the mainshock. In the weeks before the earthquake, slow-slip similar to previous events ${ }^{9,10}$ was not observed. Early aftershocks were observed in the first few days across the peninsula, but are dominantly in the region surrounding and downdip of the earthquake hypocentre. Geomorphic coastal uplift observations and both continuous and repeat survey GPS measurements obtained in the first 5-12 days after the event highlight large trenchward horizontal displacements up to $68 \mathrm{~cm}$ and uplift up 

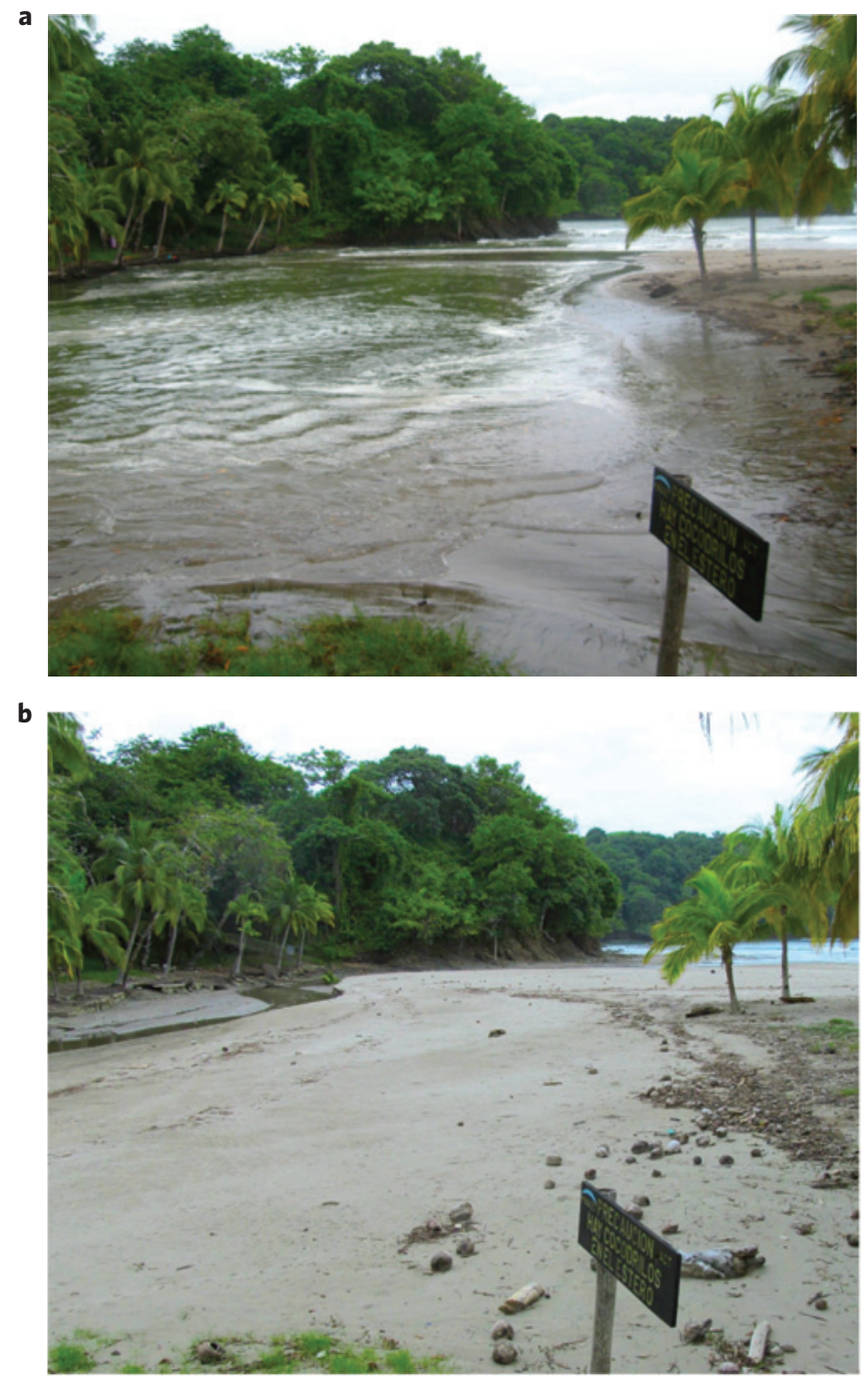

Figure 3 | Observations of earthquake-induced changes in a coastal estuary. $\mathbf{a}$, Pre- and $\mathbf{b}$, post-earthquake photographs of high tide at Playa Carrillo estuary (location shown in Fig. 2), showing the effects of coseismic uplift directly inland of the epicentre: 5 July 2012, 3:50 pm (+3.0 m tide a), 13 September 2012, 12:30 pm, (+2.4 m tide; b). The tide pictured in a was the highest for the two months preceding the earthquake. Note the coconut debris line left by this tide still visible in the post-earthquake photo in $\mathbf{b}$. After correcting for predicted tidal differences $(0.6 \mathrm{~m})$, the coseismic uplift was determined to be $0.7 \pm 0.2 \mathrm{~m}$.

to $53 \mathrm{~cm}$ along the central coast, with deformation diminishing, and uplift transitioning to subsidence farther inland (Fig. 2). The GPS also revealed a clear pivot line denoting the inland transition between vertical uplift and subsidence marking the downdip extent of major slip (Fig. 2) - a feature that occurs offshore in most large megathrust earthquakes, including the 2011 Tohoku-Oki event ${ }^{20}$. Along the central coast, uplift was more than $0.5 \mathrm{~m}$, causing visible changes in the coastline, particularly along rocky tidal platforms and estuaries (Fig. 3). This region also had the maximum late-interseismic subsidence of about $1.0 \mathrm{~cm} \mathrm{yr}^{-1}$, corresponding to almost $100 \%$ recovery of vertical strain accumulation since the last major earthquake 62 years earlier if interseismic deformation rate remained constant through the period.

The earthquake occurred in the immediate area defined by previous geodetic studies and was approximate to, but was somewhat smaller than, the expected $M_{\mathrm{w}}$ 7.7-7.8 given the spatial extent of interseismic coupling assuming constant strain accumulation since the 1950 magnitude 7.7 earthquake ${ }^{4}$. A smaller $M_{\mathrm{w}} 6.9$ earthquake occurred in central Nicoya in 1978, having about $0.7 \mathrm{~m}$ slip $^{2}$. Although relatively small, this event may have been sufficiently large to modestly postpone the most recent event as it accounts for approximately $16 \%$ of the accumulated strain energy between 1950 and 2012 (ref. 4). Details of the seismic, geodetic and geomorphic data and subsequent reduction methods are included in the electronic supplement.

Inversions of three-dimensional displacement vectors from 18 continuous and 21 campaign GPS sites (Fig. 2) using the same model geometry as developed in a previous study ${ }^{4}$ show that the earthquake ruptured the landward extent of the most recently defined locked patch along the central coast of Nicoya (Fig. 4a). The locked patch, identified as the area creeping at less than $50 \%$ of the convergence rate, has a rather complex geometry that corresponds to characteristics of the incoming plate, as identified by magnetic lineations ${ }^{21}$. The coseismic slip distribution as determined from strong ground motion and teleseismic waveforms, and a sub-network of 11 GPS stations, including 9 high-rate results ${ }^{22}$, agrees well with that shown here from the static GPS.

An interesting aspect of this earthquake is that the rupture was not obstructed by a well-documented transition in subduction crust origin and morphology. The northwestern segment of the incoming plate was generated at the East Pacific Rise (EPR), whereas the southeastern segment was generated along the CocosNazca spreading centre (CNS). Although the plates are of similar age (20-24 Myr old), differences exist in the orientation of the subducting crusts relative to their plate generation axes as identified by seafloor magnetic anomalies. Trench-parallel subduction of anomalies occurs along the EPR section, whereas trench-perpendicular subduction occurs along the CNS section ${ }^{21}$. Along the subduction interface, the transition between subducted segments corresponds to differences previously noted in the depth of microseismicity ${ }^{5}$, predicted thermal profiles ${ }^{23}$, tomographically defined slab morphology ${ }^{24}$ and long-term net forearc uplift over multiple seismic cycles ${ }^{25}$. Along with an estimated $35^{\circ} \mathrm{C}$ increase in temperature $\mathrm{e}^{23}$, an approximate $5 \mathrm{~km}$ upward shift in the depth of the megathrust interface ${ }^{5,24}$ occurs along the transition from EPR to CNS crust at seismogenic depths. Although not well understood, this transition corresponds to a change in the interseismic coupling immediately offshore, with a fully locked patch occurring along the EPR segment and significant creep to the south past the EPR-CNS transition ${ }^{4}$. Landward of the coast, the interseismic coupling also transitions between EPR and CNS segments. Here, along the EPR subducted segment, there seems to be a creeping section that corresponds to ongoing microseismicity before becoming more coupled again immediately downdip ${ }^{4}$. However, along the CNS segment, coupling remains high through the zone of microseismicity before hitting the downdip limit at about $30-35 \mathrm{~km}$ depth.

The earthquake, although initiating immediately offshore, ruptured primarily beneath land with up to $4.3 \mathrm{~m}$ of thrust and $1.1 \mathrm{~m}$ right-lateral motion. On average the large slip region includes $1.9 \mathrm{~m}$ of thrust and $0.3 \mathrm{~m}$ of right-lateral motion, as calculated by averaging the rake of the rupture area with slip $\geqslant 1 \mathrm{~m}$ (Fig. $4 \mathrm{~b}$ ), and similar to the rake of $102^{\circ}$ Centroid Moment Tensor determined using local seismic data ${ }^{18}$. The area of coseismic slip exceeding $2 \mathrm{~m}$ covers the along-strike and downdip extent of interseismic locking ${ }^{4}$. Updip and immediately offshore there seems to be no coseismic rupture, however some slip is required farther offshore, but is mostly outside our area of resolution (Supplementary Fig. 3). The offshore locked segment ${ }^{4}$ does not seem to have ruptured (white contours in Fig. $4 \mathrm{~b}$ ) and remains an area of possible concern. 


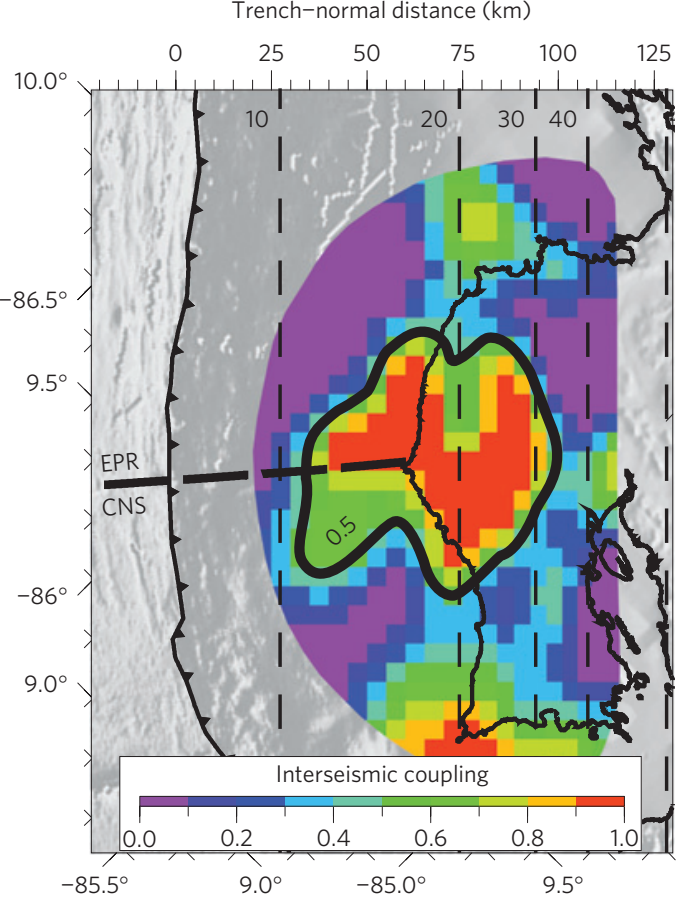

b

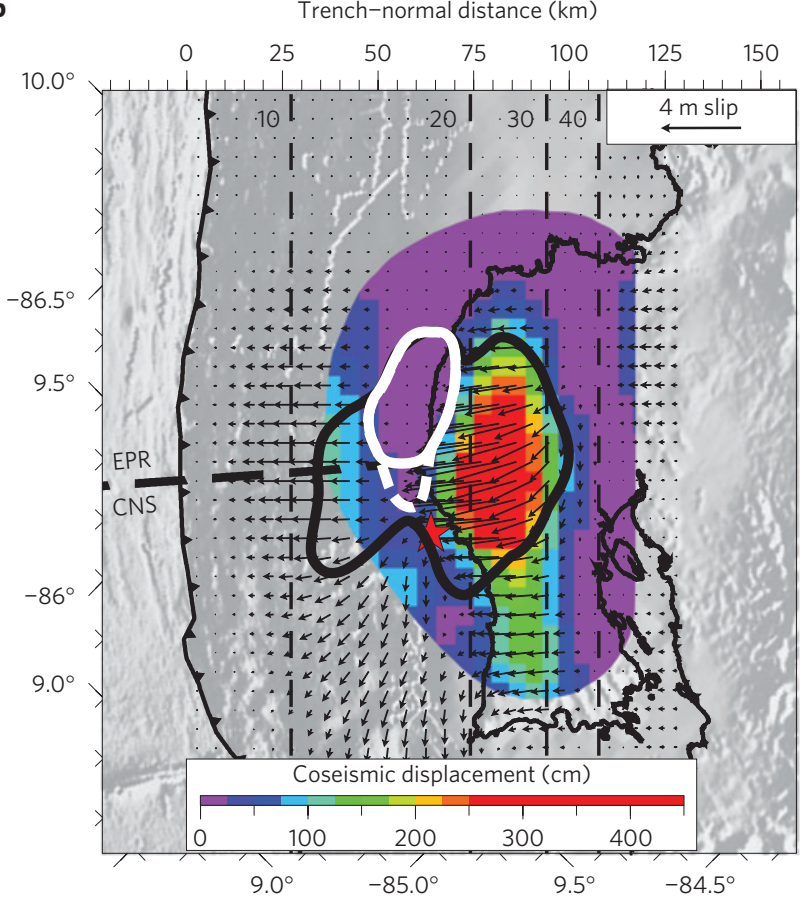

Figure 4 | Comparison of late-interseismic coupling and coseismic displacement. a,b, Interseismic coupling ${ }^{4}$ (a) and the preferred coseismic slip model (b) for the 2012 Nicoya earthquake (colour contours and vectors) are shown in the area of maximum resolution (see Supplementary Fig. 3). Depth to interface is shown as vertical dashed contours $(\mathrm{km})$. Downgoing lithosphere is generated by the EPR to the northwest and CNS to the southwest. The central $50 \%$ coupling area (thick black line marked 0.5 ) from $\mathbf{a}$ is repeated in $\mathbf{b}$. A strongly coupled region immediately offshore did not seem to rupture during the 2012 earthquake (white contours). Positive coordinates denote latitude in ${ }^{\circ} \mathrm{N}$, negative coordinates denote longitude in ${ }^{\circ} \mathrm{E}$.

The apparent remaining locked patch immediately offshore Nicoya is large enough to generate a substantial earthquake (up to $M_{\mathrm{w}}$ 6.9), but decreasing resolution offshore prohibits an accurate assessment of the extent of this slip deficit. Such an event could slip as long-term postseismic afterslip or occur as a single, unusually large aftershock. Alternatively, this segment may remain locked and fail as part of a future large megathrust earthquake similar to the occurrence of the 2010 Mentawai earthquake following the 2007 Sumatran earthquake ${ }^{26}$, or in one or many aseismic slow-slip events, similar to those identified before the event ${ }^{9}$. Along-strike to the northwest and southeast of the Nicoya earthquake, adjacent locked patches ${ }^{4}$ may also slip, in similar near-magnitude-7 events. Outside the area of resolution shown in Fig. 4 little can be said about the near-term earthquake potential and the possibility of a near-trench rupturing tsunami earthquake occurring offshore, similar to the 1992 Nicaraguan event immediately to the northwest ${ }^{27}$, cannot be excluded. To constrain the potential for strain accumulation, continued geodetic observations in the area and along the sea floor are necessary ${ }^{28}$.

Given the early establishment of seismic and geodetic networks, this event constitutes a success for international scientific efforts to illuminate subduction megathrust behaviour before large earthquakes. In Nicoya, nearly 20 years of seismic, geodetic and geomorphic data were collected in the late-interseismic period and now unprecedented data are available to study coseismic rupture and postseismic processes ${ }^{29}$. Many questions remain about the overall earthquake efficiency of subduction zones, particularly in Central America where earthquakes are estimated to account for less than $25 \%$ of the geodetically determined plate convergence rates ${ }^{30}$. By evaluating ongoing deformation and earthquakes in the region, Nicoya becomes an opportunity to establish a unique seismic cycle observatory.

As the result of two decades of locally focused scientific discovery and infrastructural development, the location and approximate magnitude of the 2012 Nicoya earthquake were anticipated. The event ruptured the onland extent of the previously locked section along the central Nicoya Peninsula bounded by recently observed episodic slow-slip events. An area of unrecovered strain accumulation may remain offshore, with the potential for a future large aftershock. The results here show the utility of detailed near-field geodetic observations and modelling for identifying major earthquake potential along interplate regions. For most other subduction environments similar near-field measurements would require substantial seafloor geodetic observations.

\section{Methods}

Details of the earthquake location method, GPS and geomorphic data reduction and inversion methods are included in an electronic supplement and are only briefly summarized here.

Earthquake locations. Local earthquakes recorded by the UC Santa Cruz and Georgia Tech seismic networks were located within a local three-dimensional velocity model $^{24}$ (Fig. 1).

GPS displacements and slip solutions. Coseismic displacements of the Nicoya earthquake were determined by examining differential daily solutions of processed campaign and continuous sites and are reported in Supplementary Table 1. Most continuous GPS data were reported the day after the earthquake, whereas campaign GPS data were used between 4 and 14 days after the event, with the shortest delays for sits above and near the main slip patch. For data where a large pre-seismic gap exists, the interseismic velocity field was used to correct for pre-event conditions. Using the GPS displacement fields a linear inversion scheme that trades off roughness between individual slip patches was carried out using the same model geometry as in ref. 4 . The optimal solution was chosen as one where a reasonable trade-off between increased solution misfit and increased model smoothness is obtained.

Geomorphic uplift. Uplift measurements were made at a total of 22 coastal sites between 5 and 16 days following the earthquake. Depending on the conditions of the site, one or any combination of six methods was used to determine relative changes in ground level. Offset measurements were corrected for tidal differences, differential wave run-up and post-seismic deformation as observed by near-field GPS sites. 
Received 18 June 2013; accepted 13 November 2013; published online 22 December 2013

\section{References}

1. Nishenko, S. P. Circum-Pacific seismic potential: 1989-1999. Pure Appl. Geophys. 135, 169-259 (1991).

2. Protti, M., Guëndel, F. \& Malavassi, E. Evaluación del potencial sísmico de la Península de Nicoya (Editorial Fundación UNA, 2001).

3. Norabuena, E. et al. Geodetic and seismic constraints on some seismogenic zone processes in Costa Rica. J. Geophys. Res. 109, 1-25 (2004).

4. Feng, L. et al. Active deformation near the Nicoya Peninsula, northwestern Costa Rica, between 1996 and 2010: Interseismic megathrust coupling. J. Geophys. Res. 117, B06407 (2012).

5. Newman, A. et al. Along-strike variability in the seismogenic zone below Nicoya Peninsula, Costa Rica. Geophys. Res. Lett. 29, 1977 (2002).

6. Schwartz, S. Y. \& DeShon, H. R. in The Seismogenic Zone of Subduction Thrust Faults (eds Dixon, T. \& Moore, J. C.) 576-599 (Columbia Univ. Press, 2007).

7. Ghosh, A., Newman, A. V., Thomas, A. M. \& Farmer, G. T. Interface locking along the subduction megathrust from b-value mapping near Nicoya Peninsula Costa Rica. Geophys. Res. Lett. 35, L01301 (2008).

8. DeMets, C., Gordon, R. G. \& Argus, D. F. Geologically current plate motions. Geophys. J. Int. 181, 1-80 (2010).

9. Outerbridge, K. C. et al. A tremor and slip event on the Cocos-Caribbean subduction zone as measured by a global positioning system (GPS) and seismic network on the Nicoya Peninsula, Costa Rica. J. Geophys. Res. 115, B10408 (2010)

10. Jiang, Y. et al. Slow slip events in Costa Rica detected by continuous GPS observations, 2002-2011. Geochem. Geophys. Geosyst. 13, Q04006 (2012).

11. Brown, J. R. et al. Deep low frequency earthquakes in tremor localize to the plate interface in multiple subduction zones. Geophys. Res. Lett. 36, L19306 (2009)

12. Walter, J. I., Schwartz, S. Y., Protti, J. M. \& González, V. Persistent tremor within the northern Costa Rica seismogenic zone. Geophys. Res. Lett. 38, L01307 (2011).

13. Walter, J. I., Schwartz, S. Y., Protti, J. M. \& Gonzalez, V. The synchronous occurrence of shallow tremor and very low frequency earthquakes offshore the Nicoya Peninsula, Costa Rica. Geophys. Res. Lett. 40, 1-6 (2013).

14. Lundgren, P. et al. Seismic cycle and plate margin deformation in Costa Rica: GPS observations from 1994 to 1997. J. Geophys. Res. 104, 28915-28926 (1999).

15. Iinuma, T. et al. Inter-plate coupling in the Nicoya Peninsula, Costa Rica, as deduced from a trans-peninsula GPS experiment. Earth Planet. Sci. Lett. 223, 203-212 (2004).

16. Laboratorio de Ingeniería Sísmica. http://www.lis.ucr.ac.cr/index.php?id= 665 (2012).

17. Chacón-Barrantes, S. E. \& Protti, M. Modelling a tsunami from the Nicoya, Costa Rica, seismic gap and its potential impact in Puntarenas. J. South Am. Earth Sci. 31, 372-382 (2011)

18. Chaves, E. J. et al. Determination of earthquake source parameters using local and regional data: Seismic moment and rupture directivity of the $M w=7.6$ Nicoya Earthquake, Costa Rica. AGU Meeting Am. [abstract] (2013).

19. Ekström, G., Dziewonski, A. M., Maternovskaya, N. N. \& Nettles, M. Global seismicity of 2003: Centroid-moment-tensor solutions for 1087 earthquakes. Phys. Earth Planet. Inter. 148, 327-351 (2005).

20. Simons, M. et al. The 2011 Magnitude 9.0 Tohoku-Oki Earthquake: Mosaicking the megathrust from seconds to centuries. Science 332, 1421-1425 (2011).
21. Barckhausen, U., Ranero, C., von Huene, R., Cande, S. \& Roeser, H. Revised tectonic boundaries in the Cocos Plate off Costa Rica: Implications for the segmentation of the convergent margin and for plate tectonic models. J. Geophys. Res. 106, 19207-19220 (2001).

22. Yue, H. et al. The 5 September 2012 Nicoya, Costa Rica Mw 7.6 earthquake rupture process from joint inversion of high-rate GPS, strong-motion, and teleseismic $P$ wave data and its relationship to adjacent plate boundary interface properties. J. Geophys. Res. 118, 5453-5466 (2013)

23. Spinelli, G. A., Saffer, D. M. \& Underwood, M. B. Hydrogeologic responses to three-dimensional temperature variability, Costa Rica subduction margin. J. Geophys. Res. 111, B04403 (2006).

24. DeShon, H. R. et al. Seismogenic zone structure beneath the Nicoya Peninsula, Costa Rica, from three-dimensional local earthquake P- and S-wave tomography. Geophys. J. Int. 164, 109-124 (2006).

25. Marshall, J. S. \& Anderson, R. S. Quaternary uplift and seismic cycle deformation, Peninsula de Nicoya, Costa Rica. Geol. Soc. Am. Bull. 107, 463-473 (1995).

26. Newman, A. V., Hayes, G., Wei, Y. \& Convers, J. A. The 25 October 2010 Mentawai Tsunami Earthquake, from real-time discriminants, finite-fault rupture, and tsunami excitation. Geophys. Res. Lett. 38, L05302 (2011).

27. Kanamori, H. \& Kikuchi, M. The 1992 Nicaragua earthquake: A slow tsunami earthquake associated with subducted sediments. Nature 361, 714-716 (1993).

28. Newman, A. V. Hidden depths. Nature 474, 441-443 (2011)

29. Dixon, T. H. et al. Detailed data available for recent Costa Rica earthquake. Eos. Trans. AGU 94, 17-18 (2013).

30. Pacheco, J., Sykes, L. \& Scholz, C. Nature of seismic coupling along simple plate boundaries of the subduction type. J. Geophys. Res. 98, 14133-14159 (1993).

\section{Acknowledgements}

We thank the field team including S. Polster, J. Richardson, D. Voytenko, G. Barcheck, S. Morrish, E. Menjivar and E. Hernandez. We thank the now finished NSF MARGINS programme for providing regional focus for studying seismogenic zone processes in Costa Rica. Support to S.Y.S. and T.H.D. was provided by NSF no. 0847382 and 1140261 , support to J.S.M. was provided by NSF no. 0948312 and support to A.V.N. was provided by NSF no. 1262267 and 0847382 .

\section{Author contributions}

M.P. and V.G. provided original insight of Nicoya earthquake vulnerability and long-term dedication and support to field research in Nicoya, including the post-earthquake campaign. A.V.N. obtained NSF funds, managed the post-earthquake field campaign and coordinated efforts on this manuscript. S.Y.S. and T.H.D. established and maintain much of the Nicoya seismic network and the continuous GPS network, respectively. J.S.M. carried out pre- and post-earthquake field geomorphic studies and provided final geomorphic results. A.V.N., S.Y.S., T.H.D., M.P. and J.S.M. provided individuals for the field campaign. J.I.W. carried out early aftershock analysis and provided Fig. 1. S.E.O. provided initial rapid GPS solutions for rapid field assessment. R.M. provided final GPS solutions. L.F. provided rapid and final inversion models for coseismic slip and Fig. 4, Supplementary Figs 2 and 3. A.V.N. wrote the paper with all authors adding contributions to the final version and Supplementary Text.

\section{Additional information}

Supplementary information is available in the online version of the paper. Reprints and permissions information is available online at www.nature.com/reprints. Correspondence and requests for materials should be addressed to A.V.N.

\section{Competing financial interests}

The authors declare no competing financial interests. 